\title{
On the Technologies and Systems for Student Attendance Tracking
}

\author{
Zoran Kotevski, Natasa Blazheska-Tabakovska, Andrijana Bocevska, Tome Dimovski \\ "St. Kliment Ohridski" University - Bitola \\ Faculty of information and communication technologies, Bitola, R. Macedonia \\ E-mail: \{zoran.kotevski, natasa.tabakovska, andrijana.bocevska, tome.dimovski\}@ fikt.edu.mk
}

Received: 08 November 2016; Accepted: 09 August 2018; Published: 08 October 2018

\begin{abstract}
Manual student attendance tracking, by calling student names from a check list or taking students' signs on a paper, has gone into history. Nowadays, modern technologies have already enabled the development of various automatized attendance tracking systems. These technologies include: Radio-Frequency Identification (RFID), Biometric (fingerprint, face or voice recognition) Barcode identification and Bluetooth communication technologies, that are implemented over an IP infrastructure as a platform. But, all these technologies perform in a different manner and exhibit certain functional limitations considering the given implementation. The main motivation for this research was to explore the possibilities for overcoming the issues of current systems for attendance tracking, considering the limitations of the technologies employed. Hence, the core contribution of this research can be considered as a fourfold, i.e. i) it presents the most frequently used technologies in the development of attendance tracking systems, ii) it reviews a range of existing student attendance tracking systems, iii) it defines criteria for performance evaluation of the technologies employed in student attendance tracking, from a perspective of educational institutions, and iv) it evaluates the mostly used technologies according to the predefined functional criteria. As a summary of the evaluation it provides directions for future development of a student attendance tracking system that would address the explored issues and functional limitations.
\end{abstract}

Index Terms - Student attendance tracking, RadioFrequency identification (RFID), Bluetooth, Barcode, Fingerprint recognition, Voice recognition, Face recognition, IP technologies.

\section{INTRODUCTION}

Managing attendance records is a quite difficult task for most organizations, and maintaining an appropriate attendance tracking system is an important factor, especially for educational institutions. Newman-Ford et al [1] have already shown evidence that there is a significant correlation between students' attendance and their academic performance. There is also a claim by Marr L. and Lancaster G. [2] that the students who have poor attendance records will generally link to poor retention.

Manually taking the attendance and maintaining it for a long time adds to the difficulty of the student attendance tracking tasks, while wasting a lot of valuable time as well. For this reason, an efficient system that automates the whole process of keeping track of attendance and maintaining the records is a necessity, especially in an academic institution. Technological innovations can be very useful tools to facilitate the development of novel approaches and systems that would eliminate the disadvantages of the classical manual methods. Thus, many newer technologies have found application in attendance tracking systems, where the most commonly used such technologies include: Radio-Frequency Identification (RFID), Bluetooth, Barcode identification, and several biometric technologies, such as: fingerprint recognition, face recognition and voice recognition. All these technologies present adequate performance and provide firm foundation for building student attendance tracking systems, but, since they all differ in certain functional aspects, they exhibit various performance issues and drawbacks that need to be carefully considered in the process of planning and development of a system for maintaining attendance records. Considering the differences of the aforementioned technologies, in this research, we briefly elaborate their functioning, and we review a comprehensive list of related systems for student attendance tracking, while providing their main performance characteristics and drawbacks in the real world implementations. Furthermore, we define multiple evaluation criteria based on the functional requirements of academic environments, and we evaluate the presented technologies. Beside the detailed review of technologies and systems for student attendance tracking, and the performed evaluation, as a summary of the research we outline direction for future development of an attendance tracking system intended for educational institutions, which we believe it would addresses the performance issues of related technologies and existing systems.

The rest of this paper is organized as follows: In Section 2 we discuss the functional aspects of the technologies that are exploited for development of attendance tracking systems. Section 3 is a state of the art of a larger list of existing attendance tracking systems, which includes their advantages and drawbacks. In 
section 4 we define evaluation criteria for student attendance tracking on the basis of the functional requirements of an academic environment, and we evaluate the technologies employed. Section 5 concludes the research with a summary of contribution and outlines directions for future development of a student attendance tracking system that would address the issues of related systems.

\section{TECHNOLOGIES EMPLOYED IN ATTENDANCE TRACKING SYSTEMS}

In present times, the most commonly employed technologies in student attendance tracking systems include RFID, Bluetooth and Barcode, as well as several techniques in the biometric domain, such as fingerprint recognition, voice recognition and face recognition. Furthermore, the techniques that use human physical data are receiving increasing attention as authentication methods that are more convenient than the conventional methods, such as a password or ID cards. As stated by Srivastava et al. [3], this is due to the fact that biometric personal authentication uses data taken from a person's measurements, which is unique to the individual and remains the same throughout one's life. The human face, eye, iris, fingerprint, hand geometry, voice, DNA, retina are among the many examples of objects that have been found useful to serve as an undisputed biometric keys, because of their uniqueness from person to person (Ganguly et. al. [4]).

In the following lines we elaborate the main concepts describing each particular technology, the ways it functions, the basic requirements and its main characteristics.

\section{A. Radio-Frequency identification}

RFID, including NFC (Near-field Communication) [5], is a technology that is used to identify a person or objects using radio waves. RFID is used to collect information automatically by Radio-Frequency (RF) data communication between a mobile object (RFID tag) and an RFID reader, to identify the entity and track its records. The system typically includes radio-emitting RFID tags (transponder), RFID readers (interrogator), and a controller (host) that most often takes the form of a PC or a workstation with an appropriate software (Hunt et al. [6], Rostampour et al. [7]). An RFID tag is attached to each object that is being tracked, and it emits a unique electromagnetic signature that is captured by the RFID reader. A typical reader is a device that has one or more antennas that emit radio waves and receive signals back from the RFID tag. The host computer processes the respective information as needed. The RFID reader includes a small RF transmitter which transmits an encoded radio signal to interrogate the RFID tags, and a RFID receiver which receives the message and responds with its identification information. Individual systems operate at specific frequencies, which depend on frequency allocations regulated by regional authorities.

RFID systems have three fundamental capabilities: the system has the ability to wirelessly identify people and objects without human manipulation, automatically generate data that can be used to track and locate tagged items, or facilitate specific types of RFID tags to aid to environmental monitoring capabilities.

\section{B. Bluetooth technology}

Bluetooth is a standardized technology that is used to create temporary (ad-hoc) short-range wireless communication systems (Harte [8]). Bluetooth technology was created as an open standard to allow connectivity and collaboration between disparate products and industries. Bluetooth was conceived as a wireless alternative to data cables by exchanging data using radio transmissions. The range of operation of Bluetooth technology can extend up to 100 meters and sometimes even more, but in its most common implementations in mobile devices it has a range of only 10 meters. Bluetooth technology consumes low amount of power and is therefore highly appropriate and intensively implemented in cell phones and other batteryoperated devices. The technology provides voice, data, and audio communications between paired devices.

\section{Barcodes}

A linear barcode refers to a way of encoding numbers and letters in a sequence of variable width bars and spaces so that it can be read, retrieved, processed, and validated using a computer. The development of $2 \mathrm{D}$ barcode enabled storing of large amount of data in a small area to support information distribution and detection without accessing a database. But, 2D barcodes require a sophisticated devices for decoding. As elaborated by Gao et al. [9], in general, there are two types of 2D barcodes: a) stacked 2D barcodes, such as Code 49 and PDF417, and b) Matrix 2D barcodes, such as Data Matrix and QR Code. Barcodes are used widely because barcode technology and barcode processing provide fast, simple, inexpensive and accurate tool to enter data without using a keyboard, and easily decodes text information by the use of electronic readers.

\section{Fingerprint recognition}

Fingerprint recognition or fingerprint authentication is a process that is used for a very long time because of the simplicity and accuracy of fingerprint readings (Lee and Gaensslen [10]). Fingerprint identification is based on two factors: i) persistence: the basic characteristics and features do not change with time; ii) individuality: fingerprint of every person in this world is unique (Pankanti et al. [11]). The process of fingerprint recognition tries to find a match between fingerprints of users from its existing database. The analysis of the fingerprints includes matching the print patterns to be compared in various settings. There are a number of different strategies through which fingerprint identification can be conducted, among which verification through minutia points is the most simple and easy to use (Karray et al. [12]). Ridge endings, ridge bifurcations and ridge divergence are some of the types of 
minutia points. A fingerprint recognition process consists of three phases: the first phase is the fingerprint identification and transmission of templates over the network; second phase is the database management on the server; and the third phase includes report generation. A fingerprint recognition system typically includes: a fingerprint sensor device (usually including LCD screen) that is used to capture the fingerprints; a decision making software (a software that makes the comparison and perform identification); and a database with fingerprint feature set.

\section{E. Face recognition}

Face recognition process tries to automatically detect and match a face from a digital image or a video frame with data from an existing database. Here, the facial features from a camera image are compared to the facial features from a database image. Thus, three components are essential for the system's functionality: a camera that is used to take images; a micro-controller that collects images and sends them to the server; and a server that stores images, while performing feature extraction, classification and face recognition as well (Kainz et al. [13]). The Camera is connected to the micro-controller and based on a predefined time interval it shoots an image. Once an image is shot it is transferred to the micro-controller, which subsequently sends data to the server. The server performs processing of image data, feature extraction and classification. The server then evaluates the image or image sequence based on the image data as provided from the database. The two main approaches of recognition algorithms include geometry, which is a method of searching for distinguishing features, and photometry, which is a statistical approach that distills an image into values and compares them to the templates to eliminate variances.

\section{F. Voice recognition}

The voice is a unique feature of every individual and using voice recognition it is possible to identify a user from an existing database, by utilizing the distinct characteristics of the voice, including the pitch, time, amplitude and intensity (Mohammed and Hegarty [14]). The main advantage of such system lies in its low-cost and its utilization of voice as a unique user biometric feature. Voice is generally regarded as a less invasive and privacy-sensitive form of biometrics than fingerprints or photographs (Reda et al. [39]). The most common approaches to voice recognition can be divided into two classes: template matching and feature analysis. The first one is the simplest technique and has the highest accuracy when used properly, but it also suffers from the most limitations. A first step in this approach is for the user to speak a word or phrase into a microphone. The electrical signal from the microphone is digitized by an analog-todigital (A/D) converter, and is stored into the memory. To determine the "meaning" of this voice input, the computer attempts to match the input with a digitized voice sample, or template that has a known meaning. The program contains the input template, and attempts to match this template with the actual input using a simple conditional statement. A more general form of voice recognition is available through feature analysis and this technique usually leads to "speaker-independent" voice recognition. Instead of trying to find an exact or near-exact match between the actual voice input and a previously stored voice template, this method first processes the voice input using Fourier transforms or linear predictive coding (LPC). Then it attempts to find characteristic similarities between the expected inputs and the actual digitized voice input. These similarities will be present for a wide range of speakers and so the system needs not be trained by each new user (Klevans and Rodman [15]). The voice recognition must not be confused with speech recognition system that tries to predict the users' speech.

\section{A REVIEW OF RELATED ATtENDANCE TRACKING SYSTEMS}

The majority of modern student attendance tracking systems are based on RFID technology. In this manner, RFID is implemented in many existing systems, such as [16-28]. In these systems, all students are equipped with RFID tags, and all the classrooms are equipped with RFID readers. The process of attendance tracking is usually managed by a software running on an application server that receives events, i.e. information about the tag id, date, time, classroom location and other data concerning the class settings. The RFID reader is automatically activated at a certain time and the data is passed to a middleware for filtering of duplicates.

Implementing RFID, Patel et al. [16] claim that their system is fast, reliable and accurate and does not require physical contact between RFID reader and RFID tag. Wahab et al. [17] describe an ongoing project for recording student attendance using RFID technology. Their project called PEAS was tested in university settings, where the system is integrated with the existing system for attendance records storing and extraction. Silva et al. [18] propose a rather complex architecture and a prototype system that uses distributed RFID over Ethernet, and demonstrate how to automate an entire student attendance registration system by using RFID, in an educational institution environment. In a test scenario the authors confirm that the system works effectively and accurately. Chiagozie et al. [19] developed an RFID student attendance tracking system constructed of two components: hardware and software. The hardware unit consists of a motor interfaced with a database, and graphical user interface (GUI) that is responsible for taking and storing the data received from the RFID reader. The software unit consists of Microsoft visual studio, Microsoft .Net framework and Microsoft access database. In terms of performance and efficiency, the authors claim that this project provides a convenient method of student attendance tracking. Similar systems are also proposed in [20-22] using RFID technology. They also present comparable results and experiences.

To aid in certain functionalities Singhal and Gujral [23], propose an RFID system augmented with GSM 
capabilities, using SMS messages to inform the interested parties (parents, employers) about certain attendances on a daily basis. These RFID systems incorporating mobile communication technologies appeared to be quite common, thus conceptually, the systems in [24-25] are similar attendance tracking solutions. For example, Tiwari et al. [24] propose a hybrid system that employs RFID, GPRS and Web technologies. RFID is used to detect the RFID tag that is unique for each student, and after it collects all the respondent information the data is transferred via GPRS to a web server for storing. The authors claim that using GPRS for data transfer is quite cheap and exhibits reduced complexity of up to $50 \%$ compared to the case of a pure RF technology. Similarly as in [24], Yadav et al. [25] use a combination of RFID and GSM technologies. A standard two component RFID system, consisting of RFID tag and RFID reader, is used for student and teacher attendance tracking, while the GSM module is used for sending student attendance information to the parents via the GSM network.

Differently from [21], Mohammed et al. [26] and Kassim et al. [27] augment the RFID based student attendance systems with current web technologies to enable the teachers' real-time access to the required reports. The system in [26] is built using Microsoft platform (IIS, ASP.NET and Microsoft SQL server), while in [27] the system is based on open source technologies, such as MySQL server.

On the other hand, Saparkhojayev and Guvercin [28] developed an interesting, non-standard RFID based student attendance tracking system that is supported by some form of face detection and recognition techniques. When students enter the classroom, the RFID-reader automatically reads their RFID-cards and the Web camera takes their photos. These photos and ID's are sent to a PC, where the system compares their information with information stored in the database management system (DBMS) according to their ID's that were assigned to them. Eventually, the professor will submit all the information collected, and the DBMS will have a record of who came and who failed to come to class on any given day.

Oppositely to RFID, Bhalla et al. [29] propose a Bluetooth based attendance tracking system that uses a software application installed on the instructor's mobile telephone which enables querying students' mobile telephone via Bluetooth connections. Through transfer of students' mobile telephones' Media Access Control (MAC) addresses to the instructor's mobile telephone, presence of the student can be confirmed. Moreover, detailed records of a student's attendance can also be generated for printing and filing. The authors also state that their system is low cost, low power and sufficiently robust solution. Since the system uses Bluetooth technology it is restricted to 10 meters of common functioning, while the restriction of registering student by the MAC addresses of their phones requires constant updates because the student are prone to changing their mobile devices very frequently.

Subramaniam and Hassan [30] proposed and developed a student attendance system (SAS) based on barcode identification. For this system each student is given a student card with a unique bar code, and each classroom is equipped with a bar code scanner. The user (student) data is then written in the system and a teacher is given the opportunity to generate variety of reports concerning the students' attendance. The authors also declare that after the initial implementation of the system there were some issues that required consideration in the next revision, but since it was in a construction phase the behavior can be considered as expected.

The systems presented in [31-37] propose somewhat different approach for student attendance tracking by using biometric technologies. These systems incorporate a fingerprint reader and after a match is determined the user (student) data is written in a database. The data transfer in [31] is realized via wired LAN network and written in a Miscrosoft SQL database, while the data transfer in the other three systems developed in [32-34] is realized wirelessly using zigbee module. The main conclusion as a drawback from these types of attendance systems confirms that the systems accuracy is a bit impaired ranging between $94 \%$ and $98.57 \%$, and the time required for each user to register is about four seconds. Two of these systems [32, 33] are also equipped with GSM modules for delivering reports to top authorities in the institution. Nawaz et al. [35] propose another biometric based solution for student attendance tracking that uses a fingerprint sensor to evaluate attendees, while the actual data is stored in a data server. They use fingerprint sensors and LCD screens that are placed at the entrance of each classroom. In order to mark the attendance, students just need to place their finger on the fingerprint sensor. Upon identification, student's attendance record is stored in the database and the student is notified through the LCD screen. The system is regarded as reliable, secure, fast and efficient. Shafi et al. [36] developed an implementation of fingerprint verification over the network and its usage in student attendance tracking. In addition to this, automatically generated reports are updated on the internet and emailed to the teachers for future correspondence. The solution also integrates a Short Message Service (SMS) to inform the parents, as well as the various possibilities for reports generation. Verma and Gupta [37] developed a portable fingerprint based student attendance monitoring system that uses GSM as well. The system design includes terminal fingerprint acquisition module and attendance module, while automating its core functions, such as: fingerprint information acquisition, processing, wireless transmission, fingerprint matching and making attendance reports. After recording the attendance data, the system sends the attendance of every student to their parents' mobile phones through a GSM network.

Uddin et al. [38] have developed a voice biometric system for tracking of student attendance to classes. The model described in this research is novel and uses Euclidean distance as a mathematical background for developing voice recognition systems. Nevertheless, even though this kind of system will prevent students to abuse 
it by registering their absent classmates, the system appears to be deficiently accurate. As the authors state, the percentage of accurate recognition when students pronounce their names is only 46,15\%. Another drawback of this system type is that student registration is serial (sometimes a single student if required to pronounce its name more than once when misinterpretations occur) which leads to unwanted long durations of the registration process. Reda et al. [39] present a rather complex solution for attendance tracking in remote geographic regions. The solution, named Hyke, employs voice-biometrics, GPS location tagging and network-based timing, and provides attendance tracking in remote locations without the need for a trusted mediator on-site. The Hyke system is described as a lowcost alternative to the more expensive solutions, intended to be used mainly in the developing world regions.

Kar et al. [40] describes a method for tracking of student attendance to classes that works using face recognition technology, implementing the OpenCV library. The system provides automatic attendance recording with zero wasted time, but, as the authors report, the system's accuracy in detecting and recognizing faces in $95 \%$ for frontal face orientation which drops to zero when the angle of the face toward the camera is 72 degrees. Patil et al. [41] and Patil et al. [42] describe similar solutions for student attendance tracking based on face recognition technology. The solution in [41] is developed using MATLAB and uses GSM communications for data transfers. The system developed in [42] is claimed to be highly accurate and future integration with a GSM module is planned. Kainz et al. [43] propose an idea to estimate the number of people in a classroom using face detection algorithms and subsequently utilize face recognition algorithms to identify the present students. The solution is in a development phase and the authors believe that the system will behave as expected. It was only partially implemented on small groups of students. Tamimi et al. [44] propose a group face detection student attendance tracking system, where the camera captures a single group photo, while an image processing algorithm performs face detection and generates a list of detected student faces. The presented experiments are said to offer accuracy of face recognitions of $94.73 \%$.

Many commercial systems that implement the aforementioned technologies exist as web services that are publicly available for a certain subscription price, such as [46-50], and are a proof of the benefits that these technologies offer.

Differently from the previous approaches, Akhila et al. [45] present an IP networked solution that employs web technologies and databases for storing the attendance info, while the management interface is developed for the Android OS and installed on the teacher's mobile device. While the solution seems quite interesting and novel it has a drawback in that the teacher needs to manually check each enrolled students in the list, as present or absent. After manually checking the attendance status, the information about the particular class is stored in a database. Similar systems are presented in [51-53], which function in a way that the list of registered students must be initially entered (or imported) in the system. When a teacher creates a new class all the students are marked as present by default and the teacher needs to unmark the absent students only. All the required reports are available. This type of systems do not require any interaction from students, and the teacher is the only one with an access to it. The negative side is that the teacher must spend some time in marking all the absent students manually.

Last, but not least, the system in [54] represents a pure web based solution where each student registers her/his attendance using personal mobile device. For this kind of solution there is no need of any kind of additional hardware or software, taking into account that in present times "everyone has a smartphone". The system is publicly available, and any institution that requires attendance tracking services can open an account. The negative side of such paradigm is that the system is dependent on Internet connection, as well as the possibility for students to check in from other locations, even though the system offers certain security using students' GPS location.

The solutions presented in [46-54] mostly use Wi-Fi communication technologies, because attendees usually access the system wirelessly using a web interface, although, wired communication is perfectly viable.

In this detailed review of technologies and systems for student attendance tracking we must not forget to mention that all the systems are built on IP infrastructure. Hence, this situation completely follows the concept of converged multimedia networks, where many different services are built on a single communication platform.

In the following lines we summarize the basic drawbacks of the technologies used in student attendance tracking: a) Voice biometric systems manifest weakness of inaccurate readings and long durations of the registration process; b) RFID systems are accurate and flexible, but the negative side is the equipment needs. These system define that each student must have a unique RFID unit to be able to register, while the system requires multiple RFID receiver modules in each classroom to be able to fully operate; c) Fingerprint biometric systems have similar deficiencies as the voice biometric systems, with a somewhat better accuracy (around 96\%) and long registration times; d) Face biometric systems also exhibit insufficient accuracy of about $95 \%$ and they require that each attendee faces the camera within a certain angle, which would be influenced by the students' concentration in class; e) Barcode code systems require somewhat lower investments compared to RFID systems, but the negative side is the seriality of the registration process and the unnecessary consumption of time. f) Finally, web based systems are quite good alternative where the registration can be performed from multiple locations, but these systems are not easily customizable and depend on Internet connection, which can sometimes impose certain communication difficulties. 


\section{CRITERIA FOR PERFORMANCE EVALUATION OF DIFFERENT TECHNOLOGIES USED IN ATTENDANCE TRACKING SYSTEMS}

The development of any system begins with the definition of certain criteria which the system is intended to comply. Afterwards, the process of system planning can begin, with a careful approach taking into account each defined criteria. For the definition of the criteria for evaluation, we conducted a research and accepted three viewpoints of different requirements for student attendance tracking: i) viewpoint of an educational institution's management, ii) a teacher's viewpoint and iii) engineer's (technical and operational) viewpoint. For the purpose of the first two viewpoints, we conducted a survey in order to define the most important criteria that the development of a novel student attendance tracking system should be based on. For the first viewpoint we prepared a questionnaire for the management team, in which we addressed the financial aspects of the design, the development, the implementation and the maintenance of the attendance tracking system, as well as certain aspects related to the management of class activities that can result as an outcome from the whole process of attendance tracking. The questionnaire for the second viewpoint, conveyed among the teaching staff, revealed multiple important criteria that a student attendance tracking system should adhere to. As a result of the survey we defined several criteria, given in table 1 .

Table 1. Evaluation grades, in the range from 2 (lowest mark) to 5 (highest mark) for the referred technologies when implemented in student attendance tracking systems

\begin{tabular}{|c|c|c|c|c|c|c|c|}
\hline Criteria & RFID & Bluetooth & Barcode & $\begin{array}{l}\text { Fingerprint } \\
\text { recognition }\end{array}$ & $\begin{array}{c}\text { Voice } \\
\text { recognition }\end{array}$ & $\begin{array}{c}\text { Face } \\
\text { recognition }\end{array}$ & $\begin{array}{c}\text { Web } \\
\text { technologies }\end{array}$ \\
\hline $\begin{array}{l}\text { Purchase and implementation cost } \\
(2-\text { highest cost; } 5 \text { - lowest cost }) \mathrm{l}\end{array}$ & 2 & 4 & 3 & 3 & 4 & 3 & 5 \\
\hline $\begin{array}{l}\text { Operation and maintenance cost } \\
(2-\text { highest cost; } 5 \text { - lowest cost })\end{array}$ & 2 & 5 & 3 & 4 & 4 & 3 & 5 \\
\hline $\begin{array}{c}\text { Operating distance } \\
(2-\text { shortest distance; } 5 \text { - longest distance })\end{array}$ & 4 & 3 & 2 & 2 & 2 & 4 & 5 \\
\hline $\begin{array}{l}\text { Influence of direction and position } \\
\text { (2- highest influence; } 5 \text { - lowest influence) }\end{array}$ & 5 & 5 & 2 & 2 & 3 & 2 & 5 \\
\hline $\begin{array}{c}\text { Security } \\
(2-\text { lowest security; } 5-\text { highest security })\end{array}$ & 3 & 3 & 3 & 5 & 5 & 5 & 4 \\
\hline $\begin{array}{c}\text { Accuracy } \\
(2-\text { lowest accuracy; } 5 \text { - highest accuracy) }\end{array}$ & 5 & 5 & 5 & 4 & 3 & 3 & 5 \\
\hline $\begin{array}{c}\text { Speed } \\
(2-\text { lowest speed; } 5 \text { - highest speed })\end{array}$ & 5 & 3 & 3 & 3 & 2 & 2 & 4 \\
\hline $\begin{array}{c}\text { Simplicity of usage } \\
(2-\text { complex to use } 5 \text { - simplest to use })\end{array}$ & 5 & 4 & 5 & 5 & 5 & 5 & 4 \\
\hline $\begin{array}{c}\text { Flexibility } \\
(2-\text { lowest flexibility; } 5 \text { - highest flexibility })\end{array}$ & 4 & 4 & 4 & 4 & 4 & 4 & 4 \\
\hline $\begin{array}{c}\text { Customizability } \\
\text { (2 - lowest customizability; } \\
5 \text { - highest customizability) }\end{array}$ & 4 & 4 & 4 & 4 & 4 & 4 & 4 \\
\hline $\begin{array}{c}\text { Data safety } \\
(2-\text { lowest safety; } 5 \text { - highest safety })\end{array}$ & 4 & 4 & 4 & 4 & 4 & 4 & 4 \\
\hline \multicolumn{8}{|c|}{$\begin{array}{l}\text { Regarding the presented table of evaluation grades it must be pointed out that even though the camera, it the systems using face } \\
\text { recognition, offers greater operating distance, the distance highly and negatively influences the accuracy of such systems. Therefore, we } \\
\text { gave this metric a grade of } 4 \text {, i.e. we equalized it with the RFID technology. } \\
\text { The last three criteria refer to the backend of the system, and since all the systems are built on similar IP platforms, the performance of this } \\
\text { part of the system does not depend on the evaluated registration technologies employed. Therefore, for these criteria, all the technologies } \\
\text { share the same grades. }\end{array}$} \\
\hline
\end{tabular}

The most important criteria for the management team were two cost related criteria:

1) Purchase/Implementation Costs - It is expected that the system would be constructed and deployed with minimum financial investments. This is especially valuable for the developing countries;

2) Operating/Maintenance costs - Cost of the maintenance to keep the system fully operational as longer as possible.

Some criteria were equally important to the management team as well as to the teaching staff:

3) System security - Prevention of registration of absent students;

4) Data safety - Prevention of data loss, unauthorized access and data modification.

Considering the most important aspects of class lectures, the teacher's emphasized the following criteria:

5) Accuracy - Provision of adequate reading/recording accuracy of the attendance tracking service;

6) Speed - Provision of fast operation with the least consumption of valuable lecturing time;

7) Simplicity of usage - The system should enable easy and user friendly registration;

8) Customizability - Ability of the system to be customized to suite individual teachers' requirements. 
Concerning the technical and operational requirements, we defined the following three criteria:

9) Flexibility - Acceptance of changes in order to support variability of processes (integration with other systems, addition of other functionalities etc.).

10) Operating distance - A student attendance tracking system should operate over a distance of 20 meters, because faculties and universities often require large classrooms where sometimes the number of attendees can be even several hundred;

11) Influence of direction and position - System's readings vulnerability influenced by the alignment of students.

Some of the aforementioned criteria, are also discussed in previous related work that is concentrated on the evaluation of such systems [24].

In the next step we quantified the performance of previously elaborated technologies against the defined criteria, and evaluate their adequacy for use in attendance tracking systems. In the quantification we adopted grading values ranging from 2 to 5 .

Table 1 presents the performance evaluation of the most frequently employed technologies for student attendance tracking purposes. Besides the evaluation of the aforementioned technologies, the table also contains a column that represents an attendance tracking implementation that uses only web technologies. This column presents the evaluation of the appropriateness of a system that would not require any specific communication technology for registration of attendees, and will be built solely on IP infrastructure and wired or wireless network access. Here, we must emphasize that the grades given in the table of evaluation are not just an expression of our opinion, but a result of a carefully conveyed analysis of the experiences presented in the previously reviewed related technologies and student attendance tracking systems.

Summarization of the outcome from the previously presented review of related technologies and systems for student attendance tracking, as well as from the elaborated evaluation, leads to the conclusion that the most preferable solution for an attendance tracking system would be the solution using current web technologies. Two main reasons support this conclusion. First, all the current attendance tracking systems are built upon IP infrastructures, and the web solution is a unique implementation that does not require deployment of additional hardware. Second, considering the evaluation grades it appears that the web solution does not fall behind any other additional technology employed in student attendance tracking purposes.

\section{CONCLUSION AND FUTURE WORK}

Attendance tracking systems are valuable assets especially for educational institutions, where student attendance tracking is almost impossible to perform without a proper and automated system. Many different communication technologies are used in such systems to perform the attendance tracking, among which, the most widely used are RFID, Bluetooth, Barcode identification, fingerprint recognition, voice recognition, face recognition and web technologies. Thus, the processes of planning, design and development of a student attendance tracking system requires certain analyses in order to make the right choice for which technology to implement. For this purpose, we first briefly elaborated the technologies that are consistently employed in attendance tracking systems. Next, in order to perform the evaluation of these technologies based on experiences from real world implementations, we reviewed many existing attendance tracking systems, elaborating the specifics of their performance and user experiences. Thus, for all the technologies employed, we defined evaluation criteria from the aspect of their implementation in student attendance tracking systems, against which the evaluation was performed.

Considering the issues of current technologies and systems for student attendance tracking, and carefully taking into account each evaluation criteria, we propose a development of a web attendance tracking solution that would operate on the local network, where the students would register their presence via a web interface using their mobile devices or laptop/desktop computers. Since the system would be built on the existing IP infrastructure we expect that it would be provided with low operation and maintenance costs, thus enabling quick and simple operation, solid state security, undisputed accuracy, short registration times, custom reports generation, low maintenance requirements, easy integration with other database systems and easy backup and archiving. In this manner, we propose to base our system on free and open source technologies, such as Linux OS, HTML5, PHP scripting, MySQL database engine and Apache web server. The system would operate on the local network only, which would provide a double benefit, such as increased security and data safety. As an outcome of this evaluation, the decision in which direction to convey our future efforts for the development of such attendance tracking system, was nearly self-imposed.

\section{REFERENCES}

[1] Newman - Ford L., Fitzgibbon K., Lloyd S. \& Thomas, S. (2008). A large - scale investigation into the relationship between attendance and attainment: a study using an innovative, electronic attendance monitoring system. Studies in Higher Education, 33(6): 699-717.

[2] Marr L., \& Lancaster G. (2005). Attendance System. Learning and Teaching in Action, 4(1): 21-26.

[3] Srivastava P.C., Agrawal A., Mishra K.N., Ojha P.K., Garg R. (2013). Fingerprints, Iris and DNA Features based Multimodal Systems: A Review. International Journal of Information Technology and Computer Science (IJITCS), 5(2): 88-111.

[4] Ganguly S., \& Moulick S.R. (2012). A Review On Different Biometric Techniques. International Journal of Engineering Research \& Technology (IJERT), ISSN: 2278-0181, 1(5). 
[5] Nagashree R.N., Rao V. \& Aswini N. (2014). Near Field Communication. International Journal of Wireless and Microwave Technologies (IJWMT), 4(2): 20-30.

[6] Hunt, V. D., Puglia A., Puglia M. (2007) RFID A Guide to Radio Frequency Identification. Copyright ${ }^{\circledR}$ by Technology Research Corporation, Published by John Wiley \& Sons, Inc. Hoboken, New Jersey, USA. ISBN: 978-0-470-10764-5.

[7] Rostampour S., Namin M.E. \& Hosseinzadeh M. (2014). A Novel Mutual RFID Authentication Protocol with Low Complexity and High Security. International Journal of Modern Education and Computer Science (IJMECS), 6(1): 17-24.

[8] Harte, L. (2009). Introduction to Bluetooth: Technology, Operation, Profiles and Services, Copyright ${ }^{\circledR}$ by Altos Publihsing. ISBN: 1-932813-72-1.

[9] Gao J.Z., Prakash L. \& Jagatesan R. (2007). Understanding 2d-barcode technology and applications in m-commerce-design and implementation of a $2 \mathrm{~d}$ barcode processing solution. 31st Annual International Computer Software and Applications Conference (COMPSAC 2007), Vol. 2.

[10] Lee H.C., \& Gaensslen R.E. (2001). Advances in Fingerprint Technology. CRC Press, Taylor \& Francis Group, USA.

[11] Pankanti S., Prabhakar S. \& Jain A.K. (2002). On the Individuality of Fingerprints. IEEE transaction on pattern analysis and machine intelligence, 24(8).

[12] Karray F., Saleh J.A., Arab M.N. \& Alemzadeh M. (2007) Multi Modal Biometric Systems: A State of the Art Survey. Pattern Analysis and Machine Intelligence Laboratory, University of Waterloo, Waterloo, Canada.

[13] Kainz O., Cymbalák D., Lámer J. \& Jakab F. (2014). Visual System for Student Attendance Monitoring with Non-standard Situation Detection, 12th IEEE International Conference on Emerging eLearning Technologies and Applications ICETA 2014, December 4-5, 2014, Starý Smokovec, Slovakia.

[14] Mohammed S. \& Hegarty M. (2017). Evaluation of Voice \& Ear Biometrics Authentication System. International Journal of Education and Management Engineering (IJEME), 7(4): 29-40.

[15] Klevans R.L. \& Rodman R.D. (1997). Voice Recognition, Artech House Telecommunications Library, ISBN-13: 978-0890069271, Artech House Publishers, USA

[16] Patel R., Patel N., \& Gajjar M. (2012). Online students' attendance monitoring system in classroom using radio frequency identification technology: a proposed system framework. International Journal of Emerging Technology and Advanced Engineering, 2(2): 61-66.

[17] Wahab M.H.A., Kadir H.A., Mutalib A.A. \& Mohsin M.F.M. (2010). Design and development of portable RFID for attendance system. IEEE International Conference on Information Retrieval \& Knowledge Management (CAMP), (pp. 173-178).

[18] Silva F., Filipe V. \& Pereira A. (2008). Automatic Control of Students' Attendance in Classrooms Using RFID. IEEE Third International Conference on Systems and Networks Communications (pp. 384-389).

[19] Chiagozie O.G. \& Nwaji O.G. (2012). Radio frequency identification (RFID) based attendance system with automatic door unit. Academic Research International, 2(2): 168 .

[20] Yuru Z., Delong C., \& Liping T. (2013). The Design and Research of Student Attendance System Nodes Based on RFID. In Proceedings of the 2nd International Conference on Computer and Applications, CCA (pp. 235-238).
[21] Chand M.V.V., Meeran M.S. \& Prabaharan V. (2015). Secured Attendance Management System Using RFID Technology. International Research Journal of Engineering and Technology (IRJET), 2(8).

[22] Arulogun O.T., Olatunbosun A., Fakolujo O.A. \& Olaniyi O.M. (2013). RFID-based students attendance management system. International Journal of Scientific \& Engineering Research, 4(2): 1-9.

[23] Singhal Z. \& Gujral R.K. (2012). Anytime anywhereremote monitoring of attendance system based on RFID using GSM network. International Journal of Computer Applications, 39(3): 37-41.

[24] Tiwari A.S., Tiwari A.S., Ade N.M., Sheikh S., Patel N.R. \& Khan A.R. (2014). Optimized Design of Student Attendance System Using RFID. In International Conference on Machine Learning, Electrical and Mechanical Engineering (pp. 8-9).

[25] Yadav R., \& Nainan S. (2014). Design of RFID Based Student Attendance System with Notification to Parents Using GSM. International Journal of Engineering, 3(2).

[26] Mohammed A.A. \& Jyothi Kameswari U. (2013). Webserver based student attendance system using RFID technology. International Journal of Engineering Trends and Technology (IJETT), 4(5).

[27] Kassim M., Mazlan H., Zaini N. \& Salleh M.K. (2012), Web-based student attendance system using RFID technology. In Control and System Graduate Research Colloquium (ICSGRC), IEEE Control and System Graduate Research Colloquim (pp. 213-218).

[28] Saparkhojayev N. \& Guvercin S. (2012). Attendance Control System based on RFID-technology. International Journal of Computer Science Issues (IJCSI), 9(3): 16940814.

[29] Bhalla V., Singla T., Gahlot A. \& Gupta V. (2013). Bluetooth Based Attendance Management System. International Journal of Innovations in Engineering and Technology (IJIET), 3:2319-1058.

[30] Subramaniam H. \& Hassan M. (2013). Bar Code Scanner Based Student Attendance System (SAS). Technology of Information and Communication Jurnal (TICOM), 1(3):173-177.

[31] Shoewu O. \& Idowu O.A. (2012). Development of attendance management system using biometrics. The Pacific Journal of Science and Technology,13(1): 300-307.

[32] Potadar M.P., Marathe V.V., Khose A.S. \& Kotkar L.A. (2015). Biometric Attendance Recording and Communication System. International Journal of Innovations in Engineering and Technology (IJIET), 5(2).

[33] Joshi P.S. \& Joshi S.S. (2014). Zigbee Based Student Attendance System Using Lan Networking. IOSR Journal of Electronics and Communication Engineering (IOSRJECE), 9(6): 07-12.

[34] Talaviya G., Ramteke R. \& Shete A.K. (2013). Wireless fingerprint based college attendance system using Zigbee technology. International Journal of Engineering and Advanced Technology (IJEAT), 2(3).

[35] Nawaz T., Pervaiz S., Korrani A., Azhar-Ud-Din (2009). Development of Academic Attendence Monitoring System Using Fingerprint Identification. International Journal of Computer Science and Network Security, 9(5).

[36] Shafi Q., Khan J., Munir N. \& Baloch N.K. (2010). Fingerprint verification over the network and its application in attendance management. In IEEE International Conference On Electronics and Information Engineering (ICEIE), 2: V2-555.

[37] Verma P. \& Gupta N. (2013). Fingerprint Based Student Attendance System Using GSM. International Journal of 
Science and Research (IJSR) (pp. 2319-7064)

[38] Uddin N., Rashid M.M. \& Mostafa M.G. (2016). Development of Voice Recognition for Student Attendance. Global Journal of Human-Social Science Research: G Linguistics \& Education, 16(1).

[39] Reda A., Panjwani S. \& Cutrell E. (2011). Hyke: a lowcost remote attendance tracking system for developing regions. In Proceedings of the 5th ACM workshop on Networked systems for developing regions (pp. 15-20).

[40] Kar N., Debbarma M.K., Saha A. \& Pal D.R. (2012). Study of implementing automated attendance system using face recognition technique. International Journal of computer and communication engineering,1(2): 100.

[41] Patil M.C., Karhe M.R. \& Jain M.M. (2014). Student Attendance Recording System Using Face Recognition with GSM Based. International Journal of Research in Advent Technology, 2(8).

[42] Patil A., \& Shukla M. (2014). Implementation of Classroom Attendance System Based on Face Recognition in Class. International Journal of Advances in Engineering \& Technology (IJAET), 7(3): 974-979.

[43] Kainz O., Cymbalák D., Lamer J. \& Jakab F. (2014). Visual system for student attendance monitoring with non-standard situation detection. In 12th IEEE International Conference on Emerging eLearning Technologies and Applications (ICETA), (pp. 221-226).

[44] Tamimi A.A., AL-Allaf O.N.A. \& Alia M.A. (2015). Real-Time Group Face-Detection for an Intelligent ClassAttendance System. International Journal of Information Technology and Computer Science (IJITCS), 7(6): 66-73

[45] Akhila K., Prathyusha B., PavanKumar M. \& Amrutha M. (2013). A Novel Approach of Mobile Based Student Attendance Tracking System Using Android Application. In International Journal of Engineering Research and Technology, 2(4).

[46] http://aplusattendance.com/

[47] http://www.jollytech.com/products/school-track/

[48] http://www.mss-software.com/shop/SAT901 Student+Attendance+Tracking.htm

[49] http://www.engineerica.com/accuclass

[50] http://www.creatrixcampus.com/blog/top-10-advantagesautomated-student-attendance-system

[51] https://www.knackhq.com/attendance-tracker/

[52] http://www.bepunctual.com/class-attendance-system/

[53] https://www.myattendancetracker.com/

[54] https://www.regular.li/

\section{Authors' Profiles}

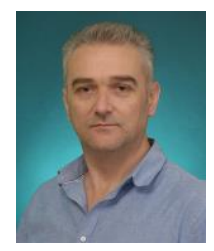

Zoran Kotevski is an Associate Professor at the Faculty of Information and Communication Technologies, "St. Kliment Ohridski" University - Bitola, R. Macedonia. $\mathrm{He}$ received his $\mathrm{MSc}$ and $\mathrm{PhD}$ degrees in Computer Science and Engineering in December, 2007 and March, 2013, respectively. His research interests include: multimedia technologies and systems, digital video and audio, computer networks, peer-to-peer technologies, web technologies, open and distance learning, computer graphics and computer vision and modeling and simulations. Dr. Zoran Kotevski has published 5 books, 3 book chapters and more than 30 research articles published in international journals, conferences and congresses, and he has participated in several EU and domestic funded projects. Dr. Zoran Kotevski currently teaches subjects in: Multimedia systems and networks, Computer graphics and computer vision and Web technologies.

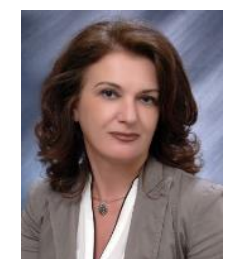

Natasha Blazheska-Tabakovska is Associate professor at the Faculty of information and communication technologies, "St. Kliment Ohridski" University in Bitola, R. Macedonia. Her field of research includes: knowledge management system, expert systems, LMS, e-learning and system analysis and design. She published a book chapter and more than 20 research articles published in international journal and conferences and she has participated in several national and international projects. Educational development: She graduated at the University "St. Kiril i Metodij", Faculty of Natural Science, Department of computer science in Skopje and received the professional title: graduate engineer of mathematics-informatics; post gradual studies were finished on "St. Kliment Ohridski" University in Bitola, Republic of Macedonia, at the Faculty of Education Bitola; she received her $\mathrm{PhD}$ degrees in Information system management at the Faculty of Administration and Information Systems Management, "St. Kliment Ohridski" University in Bitola, Republic of Macedonia in 2013.

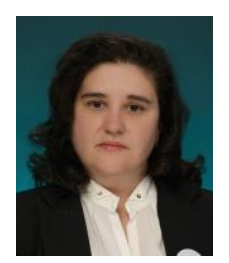

Andrijana Bocevska is an Associate Professor at the Faculty of Information and Communication Technologies, "St. Kliment Ohridski” University - Bitola, R. Macedonia. She received her $\mathrm{MSc}$ and $\mathrm{PhD}$ degrees in Mechanical Engineering in December, 2001 and October, 2012, respectively. Her research includes areas: Integrated computational methods and applications, Computer integrated manufacturing, Product engineering, technology and systems. Dr. Andrijana Bocevska has published 6 books and more than 30 research articles published in international journals, conferences and congresses and she has participated in several EU and domestic funded projects. Dr. Andrijana Bocevska currently teaches subjects in: Application software, Solid modeling, Computer integrated manufacturing, Scientific visualization in virtual environments, Product Lifecycle Management.

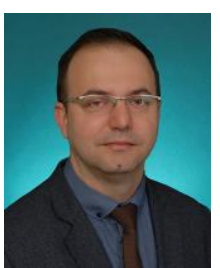

Tome Dimovski received his BSc and MSc degrees from the Technical University Gabrovo, Bulgaria, in 2004 and 2005, respectively. He received his $\mathrm{PhD}$ degrees from the Faculty of Technical Sciences, "St. Kliment Ohridski" University in Bitola, R. Macedonia in 2013. His current position is Associate professor at the Faculty of information and communication technologies, St. Kliment Ohridski University in Bitola, R. Macedonia. His research interests include Information Systems, Distributed Databases, Computer Networks and Mobile Computing.

How to cite this paper: Zoran Kotevski, Natasa BlazheskaTabakovska, Andrijana Bocevska, Tome Dimovski, "On the Technologies and Systems for Student Attendance Tracking", International Journal of Information Technology and Computer Science(IJITCS), Vol.10, No.10, pp.44-52, 2018. DOI: 10.5815/ijitcs.2018.10.06 